\title{
Perancangan Ulang dan Simulasi Tata Letak Fasilitas Produksi Gripper Rubber Seal dengan Menggunakan Algoritma Corelap, Aldep, dan Flexsim
}

\author{
Ukurta Tarigan $^{1}$, Robby Simbolon ${ }^{2}$, Meilita T Sembiring ${ }^{3}$, Uni Pratama P Tarigan $^{4}$, Nurhayati $^{2}$ \\ Sembirin $^{5}$, Indah R Tarigan 6 \\ ${ }^{1,2,3}$ Departemen Teknik Industri, Fakultas Teknik, Universitas Sumatera Utara
}

\begin{abstract}
Abstrak. PT. ABC adalah salah satu perusahaan yang berusaha di bidang manufaktur penghasil gripper rubber seal. Perusahaan ini memiliki masalah dalam tata letak lantai produksinya yaitu terdapat crossmovement dan jarak pada beberapa stasiun juga terlalu jauh yang menyebabkan aliran bahan terganggu. Permasalahan ini dapat diselesaikan dengan melakukan perbaikan tata letak lantai produksi menggunakan metode CORELAP dan ALDEP kemudian dilakukan simulasi dengan software Flexsim. Penelitian ini bertujuan untuk merancang tata letak fasilitas usulan yang dapat meminimalkan jarak perpindahan bahan dengan membandingkan efisiensi momen perpindahan tataletak aktual dengan tataletak yang diusulkan. Hasil dari penelitian ini menunjukkan adanya penurunan total momen perpindahan pada lantai produksi PT. ABC dari 14.495,08 meter/bulan menjadi 5930,19 meter/bulan dengan menggunakan algoritma CORELAP dan sebesar 7.369,7 meter/bulan pada algoritma ALDEP. Efisiensi jarak pada layout usulan juga meningkat dari $53,67 \%$ menjadi $93,74 \%$ pada algoritma CORELAP dan $78,18 \%$ pada algoritma ALDEP. Setelah dilakukan simulasi untuk mencari metode yang terbaik, didapatkan layout usulan yang terpilih merupakan layout hasil algoritma CORELAP dengan kilometers traveled per day $1,9 \mathrm{~km} / \mathrm{hari}$.
\end{abstract}

Kata Kunci: Tata Letak Pabrik, CORELAP, ALDEP, Flexsim

\begin{abstract}
PT. ABC is one of the companies that is trying to manufacture gripper rubber seal manufacturers. This company has a problem in the production floor layout, which is a crossmovement and the distance to some stations is too far which causes the flow of material to be disrupted. This problem can be solved by improving the production floor layout using CORELAP and ALDEP methods and then simulating the Flexsim software. This study aims to design a proposed facility layout that can minimize the material displacement distance by comparing the efficiency of the actual displacement moment with the proposed layout. The results of this study indicate a decrease in the total moment of displacement on the production floor of PT. ABC from 14,495.08 meters / month to 5930.19 meters / month using the CORELAP algorithm and amounting to 7,369.7 meters / month in the ALDEP algorithm. The distance efficiency in the proposal layout also increased from $53.67 \%$ to $93.74 \%$ in the CORELAP algorithm and $78.18 \%$ in the ALDEP algorithm. After simulation to find the best method, it was found that the proposed layout chosen was the CORELAP algorithm result layout with kilometers traveled per day $1.9 \mathrm{~km} /$ day.
\end{abstract}

Keywords: Factory Layout, CORELAP, ALDEP, Flexsim

Received 10 January 2019 | Revised 24 January 2019 | Accepted 24 January 2019

*Corresponding author at: Jl. Almamater Kampus USU, Medan 20155

E-mail address: ukurta.tarigan@yahoo.com 


\section{Pendahuluan}

Faktor yang sangat berpengaruh terhadap keberhasilan suatu pabrik adalah tataletak lantai produksi. Sistem pemindahan bahan merupakan salah satu hal yang mempengaruhi efisiensi tataletak lantai produksi. Peranan susunan mesin dan peralatan pada suatu pabrik juga akan sangat penting dan berpengaruh terhadap kegiatan produksi, terutama terhadap penggunaan waktu proses produksi. Proses produksi dengan kondisi mesin dan aliran produksi yang tidak beraturan menyebabkan pemindahan bahan yang tinggi. Untuk itu, diperlukan sistem pemindahan bahan yang baik dan tepat yang akan memberikan keuntungan bagi perusahaan. Untuk mendapatkan sistem pemindahan bahan yang baik dan tepat, dibutuhkan perancangan tata letak yang baik [1].

Berdasarkan pola aliran bahan pada lantai produksi PT. ABC, dimulai dari proses awal hingga akhir dapat disimpulkan bahwa pola aliran yang dipakai adalah pola aliran odd angle. Lokasi antar stasiun tidak tersusun dengan baik sehingga menyebabkan momen pemindahan bahan yang sangat tinggi. Momen pemindahan bahan yang tinggi terjadi karena ada beberapa stasiun yang mempunyai hubungan kedekatan yang erat namun ditempatkan berjauhan. Berdasarkan layout aktual PT. ABC dapat dilihat adanya crossmovement pada aliran tersebut. Sehingga dapat dikatakan bahwa tata letak lantai produksi pada PT. ABC belum efisien. Gambar 1 menunjukkan Layout Awal PT. ABC.

Peralatan material handling dapat menjadi sangat mahal, dan segala bentuk investasi perlu pengaturan biaya yang lebih baik. Solusi terbaik dapat memberikan biaya per unit termurah. Biaya material handling dapat mencapai rata-rata $50 \%$ dari total biaya operasi. Ruang produksi dapat memakan biaya sebesar $\$ 25 / \mathrm{ft} 2$ untuk pembangunan atau $\$ 5 / \mathrm{ft} 2$ untuk penyewaan dalam 1 tahun. Untuk itu, semakin baik penggunaan area, semakin sedikit area yang perlu untuk dibeli atau disewa [2]. Sistem Material Handling bertanggung jawab untuk mengangkut bahan antara workstation dengan obstruksi minimum dan menggabung semua workstation juga loka karya dalam sistem manufaktur dengan bertindak sebagai integrator dasar [3]. Hal ini juga dipahami bahwa perbaikan material handling mungkin memiliki efek positif produksi. Namun, hal ini tidak hanya produksi, tetapi juga cara karyawan melihat situasi baru. Ketika persepsi menguntungkan mungkin akan bermanfaat namun jika tidak masalah perilaku dapat muncul [4].
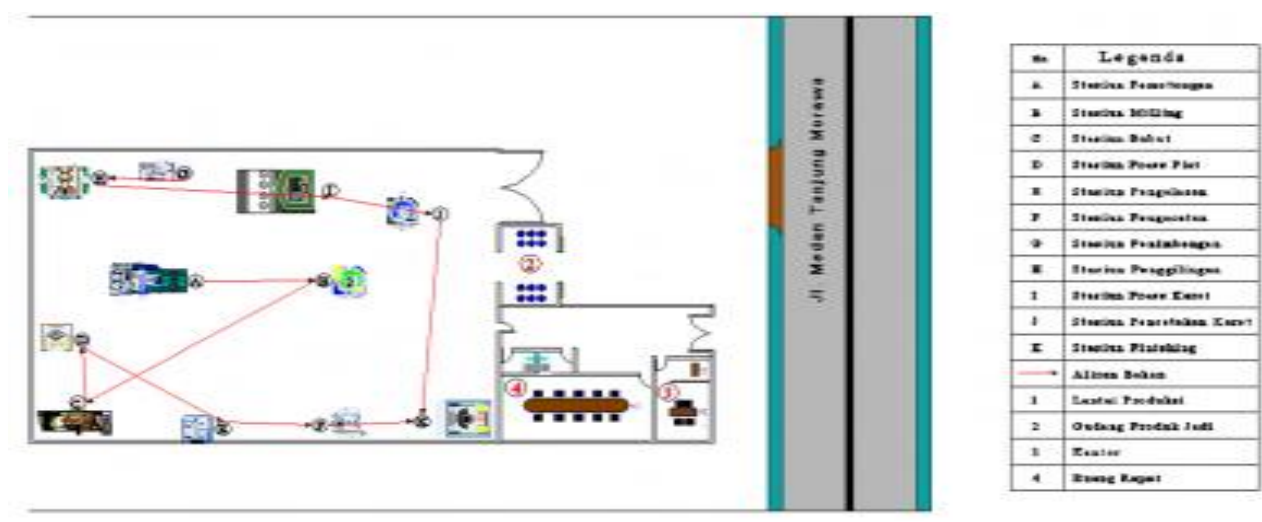

Figure 1 Layout Awal PT. ABC 
Menurut Dannang dan Dalliya (2017) Algoritma CORELAP merupakan algoritma construction yang dapat merubah data kualitatif menjadi data kuantitatif [5]. Dalam rangka penentuan fasilitas awal yang dapat diletakkan didalam layout diperlukan data keterkaitan hubungan aktivitas. Dwi agustina dan Anastasya Maukar (2007) pada penelitian di PT. X juga menggunakan algoritma CORELAP dan didapatkan hasil tata letak usulan yang lebih baik juga penghematan daya listrik [6]. Algoritma CORELAP mengurangi total perbedaan jarak pada lantai produksi dan mengurangi total biaya pemindahan bahan dibadingkan layout awal (Asifa Fitriani, Galih Prakoso, \& Anton Mulyono Azis; 2015) [7]. Penerapan algoritma CORELAP juga digunakan pada perancangan layout fasilitas pada pabrik pembuatan oven dan didapatkan hasil penghematan area sebesar $8,83 \%$ [8].

ALDEP merupakan suatu metode tata letak terkomputerisasi yang input nya berdasarkan kedekatan antar departemen. Penerapan metode $A L D E P$ ini bertujuan untuk memperoleh tata letak yang terstruktur dengan baik yang nantinya dari kedekatan- kedekatan yang telah tersusun tersebut menghasilkan material handling yang lebih efisien dari segi ongkos perpindahan bahan.

ALDEP pada dasarnya adalah sebuah algoritma konstruksi tetapi dapat juga digunakan untuk mengevaluasi dua layout. Algoritma menggunakan data dasar dari fasilitas dan membangun sebuah layout dengan menempatkan tata letak berturut- turut yang menggunakan hubungan informasi antar departemen [9].

Sebelum perbaikan dilakukan, perlu dilakukan simulasi terlebih dahulu. Simulasi ini dilakukan dengan bantuan software Flexsim. Melakukan simulasi pada sistem sekarang akan memperoleh hasil yang mudah untuk dipahami dan dikomunikasikan. Berdasarkan hasil model simulasi sistem sekarang, maka dapat dilakukan identifikasi masalah yang nantinya akan digunakan untuk memberikan solusi dan membuat model simulasi usulan agar dapat mencapai target output. Dengan mensimulasikan usulan perbaikan yang diberikan maka akan mengeliminasi proses trial and error [10].

\section{Metode Penelitian}

Penelitian action research (penelitian yang berusaha untuk memaparkan pemecahan masalah terhadap suatu masalah yang ada sekarang secara sistematis dan faktual berdasarkan data) adalah jenis penelitian yang cocok diterapkan pada permasalahan ini, yang meliputi tahap pengumpulan, penyajian dan pengolahan data serta analisis dan interprestasi pada PT. ABC dengan pendekatan studi perbandingan.

Gambar 2 menunjukkan blok diagram penelitian. 


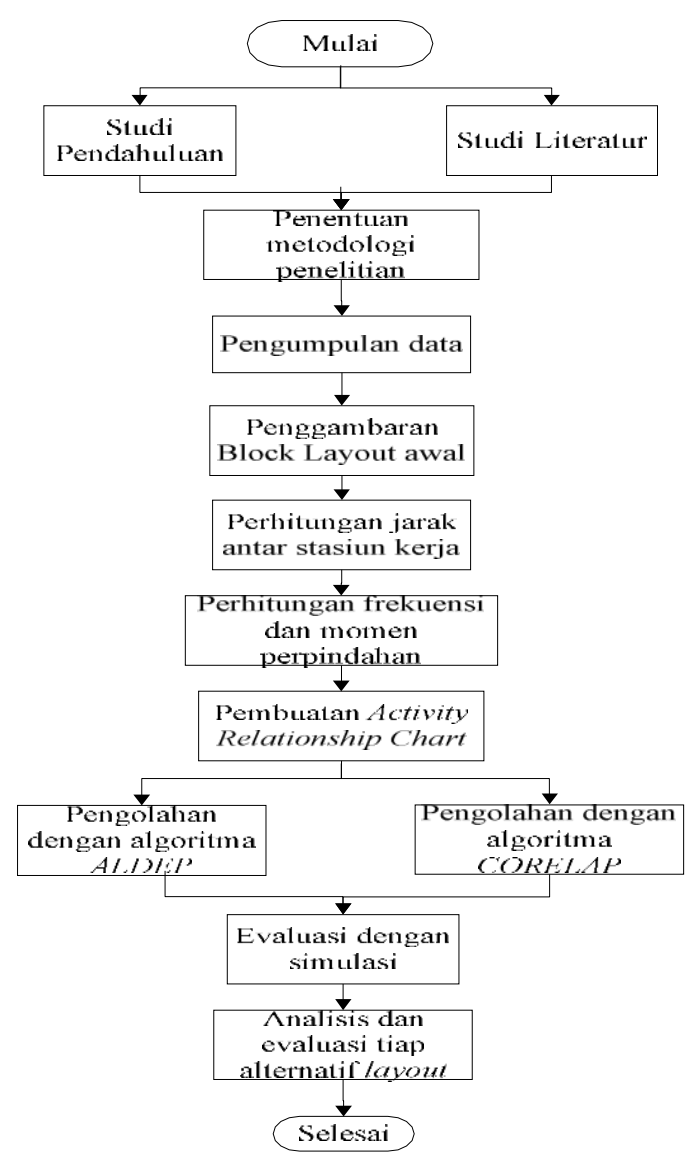

Figure 2 Block Diagram Penelitian\

Penelitian ini terdiri dari tahapan- tahapan sebagai berikut.

1) Studi Lapangan

Pengumpulan data yang dilakukan secara langsung ke lapangan tempat dilakukannya penelitian, dalam rangka memperoleh data yang sebenarnya ada dilapangan mengenai permasalahan yang ada.

2) Studi Literatur

Mendapatkan data melalui pembelajaran secara literatur serta membaca sumber- sumber data informasi lainnya yang berhubungan dengan pembahasan, sehingga diperoleh secara teoritis mengenai permasalahan utama dalam penelitian.

3) Identifikasi masalah

Merupakan langkah pertama untuk mengetahui dan memahami persoalan yang ada pada perusahaan sehingga dapat memberikan solusi pada permasalahan tersebut.

4) Perumusan masalah

Dari identifikasi masalah yang dikaji, ditarik suatu suatu rumusan masalah yang menjadi dasar dalam penentuan tujuan penelitian.

5) Penentuan tujuan penelitian

Agar dalam melakukan penelitian dapat dilakukan dengan sistematis dan tidak menyimpang dari permasalahan yang diangkat. Tujuan penelitian ini harus terjawab dalam analisis pemecahan masalah dan kesimpulan. 
6) Pengumpulan Data

Pengumpulan data yang dilakukan meliputi data primer dan data sekunder. Data yang dikumpulkan terdiri dari data dimensi/ukuran mesin dan peralatan

7). Pengolahan Data : Pembuatan Activity Relationship Chart (ARC)

Pembuatan ARC dilakukan dengan menganalisis tingkat kedekatan antar stasiun kerja/departemen. Alat ini digunakan sebagai dasar dalam pemberian nilai dan perhitungan TCR lantai produksi.

8). Pengolahan dengan Algoritma CORELAP

Penyusunan layout dengan algoritma CORELAP didasarkan pada ARC yang telah ditentukan untuk melihat hubungan kedekatan dari masing- masing departemen. Kemudian melakukan perhitungan TCR untuk setiap departemen.

9). Pengolahan dengan software ALDEP

Pengolahan data dengan software ALDEP dilakukan dengan memasukkan data tingkat kedekatan yang didapat dari ARC dan ukuran tiap stasiun kerja. Kemudian software ALDEP akan melakukan perhitungan otomatis untuk mendapatkan layout paling optimal.

10). Membandingkan layout usulan dengan simulasi flexsim

Data layout usulan yang didapatkan dari algoritma CORELAP dan ALDEP kemudian dibandingkan dengan simulasi menggunakan software Flexsim untuk mendapatkan layout usulan terbaik.

11). Menghitung nilai efisiensi layout

Usulan Untuk mendapatkan efisiensi tiap stasiun dilakukan perhitungan terhadap jarak tiap stasiun kerja pada layout usulan. Berikut ini adalah cara perhitungan efisiensi.

$$
\mathrm{E}=1-\frac{\text { Jarak usulan }- \text { Jarak Terpendek Euclidian }}{\text { Jarak Terpendek Euclidian }} \ldots . .(1)
$$

\section{Hasil dan Pembahasan}

\subsection{Perhitungan Titik Koordinat Block Layout Awal}

Berikut adalah kondisi aktual tata letak pabrik proses produksi paku di PT. ABC, yang dapat dilihat pada Gambar 3.

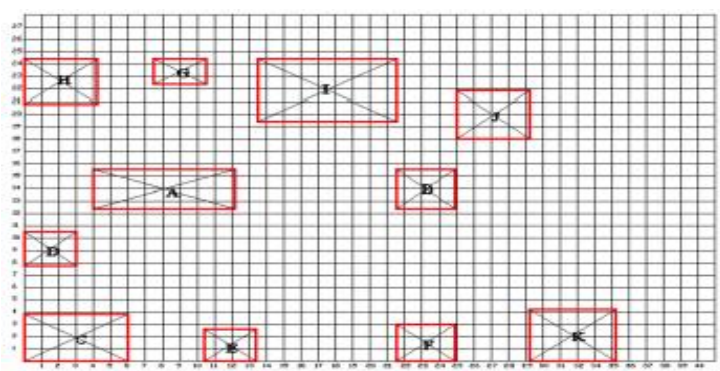

Figure 3 Block Layout Aktual 
Jarak antar stasiun kerja dihitung dengan menggunakan rumus jarak rectilinear. Rumus jarak rectilinear adalah sebagai berikut.

$$
d_{i j}=\left|x_{i}-x_{j}\right|+\left|y_{i}-y_{j}\right| \ldots \ldots(2)
$$

Hasil perhitungan jarak antar stasiun secara keseluruhan untuk tataletak awal dapat dilihat pada Tabel 1.

Table 1 Jarak Antar Stasiun Kerja

\begin{tabular}{cccc}
\hline No & Stasiun Awal & $\begin{array}{c}\text { Stasiun } \\
\text { Tujuan }\end{array}$ & Jarak Stasiun \\
\hline 1 & A & B & 15,1 \\
2 & B & C & 32,25 \\
3 & C & D & 8,73 \\
4 & D & E & 18,23 \\
5 & E & F & 11,53 \\
6 & F & K & 9,1 \\
7 & G & H & 7,65 \\
8 & H & I & 16,12 \\
9 & I & J & 11,58 \\
10 & J & K & 22,47 \\
\hline
\end{tabular}

\subsection{Penentuan Frekuensi Perpindahan Material Tiap Stasiun Kerja}

Frekuensi antar Departemen stasiun kerja diperoleh dengan menghitung rata-rata produksi selama satu bulan dibagi dengan kapasitas angkut/perpindahan dari masing-masing produk. Untuk pemindahan material antar setiap stasiun pada lantai produksi dilakukan secara manual oleh operator.

Rekapitulasi frekuensi perpindahan material antar stasiun kerja dapat dilihat pada Tabel 2.

Table 2 Jarak Antar Stasiun Kerja

\begin{tabular}{cccc}
\hline No & Stasiun Awal & $\begin{array}{c}\text { Stasiun } \\
\text { Tujuan }\end{array}$ & Jarak Stasiun \\
\hline 1 & A & B & 15,1 \\
2 & B & C & 32,25 \\
3 & C & D & 8,73 \\
4 & D & E & 18,23 \\
5 & E & F & 11,53 \\
6 & F & K & 9,1 \\
\hline No & Stasiun Awal & Stasiun & Jarak Stasiun \\
\hline 7 & Tujuan & 7,65 \\
8 & H & H & 16,12 \\
9 & I & I & 11,58 \\
10 & J & K & 22,47 \\
\hline
\end{tabular}




\subsection{Perhitungan Total Momen Perpindahan Material pada Tata Letak Awal}

Perhitungan momen perpindahan bahan dari stasiun kerja A ke stasiun kerja B dapat dilihat pada contoh sebagai berikut.

Frekuensi perpindahan bahan dari A ke b= $107 \mathrm{kali} / \mathrm{bulan}$

Jarak Perpindahan bahan dari A ke $b=15,1$ meter

Maka, momen perpindahan dari A ke B adalah

$$
\begin{aligned}
Z_{A-B} & =f_{A-B} \times d_{A-B} \ldots \ldots(3) \\
& =107 \times 15,1 \mathrm{~m} \\
& =1.615,7 \mathrm{~m}
\end{aligned}
$$

Table 3 Total Momen Perpindahan Material Antar Stasiun

\begin{tabular}{cccrc}
\hline $\begin{array}{c}\text { Stasiun } \\
\text { Awal }\end{array}$ & $\begin{array}{c}\text { Stasiun } \\
\text { Tujuan }\end{array}$ & $\begin{array}{c}\text { Frek } \\
\text { Perpind }\end{array}$ & $\begin{array}{c}\text { Jarak } \\
\text { Stasiun }\end{array}$ & $\begin{array}{c}\text { Momen } \\
\text { Perpindan }\end{array}$ \\
\hline A & B & 107 & 15,10 & $1.615,7$ \\
B & C & 107 & 32,25 & 3450,75 \\
C & D & 107 & 8,73 & 934,11 \\
D & E & 107 & 18,23 & 1950,61 \\
E & F & 107 & 11,53 & 1233,71 \\
F & G & 107 & 9,10 & 973,7 \\
G & H & 75 & 7,65 & 573,75 \\
H & I & 75 & 16,12 & 1209 \\
I & J & 75 & 11,58 & 868,5 \\
J & K & 75 & 22,47 & 1685,25 \\
\hline & & Total & & $\mathbf{1 4 . 4 9 5 , 0 8}$ \\
\hline
\end{tabular}

\subsection{Penyusunan Layout dengan Menggunakan Algoritma CORELAP}

Penyusunan layout dengan algoritma CORELAP dilakukan dnegan menghitung total jumlah hubungan kedekatan yang dinyatakan dengan Total Closeness Rating (TCR) sebagai dasar perhitungan dalam memilih penempatan stasiun kerja. Block layout usulan dari CORELAP ditunjukan pada gambar 4 .

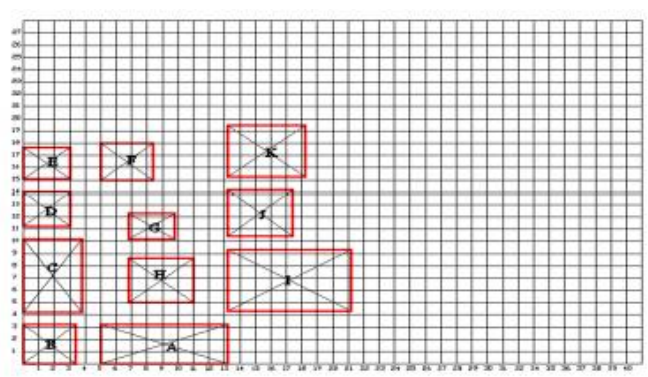

Figure 4 Block Layout Hasil Algoritma

Table 4 Jarak Antar Stasiun Kerja dengan Algoritma CORELAP

\begin{tabular}{llll}
\hline Stasiun Awal & $\begin{array}{l}\text { Stasiun } \\
\text { Tujuan }\end{array} \quad$ Frej Perpind & Jarak Stasiun & $\begin{array}{l}\text { Momen } \\
\text { Perpindan }\end{array}$
\end{tabular}

$\begin{array}{lllll}\mathrm{A} & \mathrm{B} & 107 & 15,1 & 1.615,7\end{array}$




\begin{tabular}{lllll} 
B & C & 107 & 32,25 & 3450,75 \\
\hline C & D & 107 & 5,86 & 627,02 \\
D & E & 107 & 3,71 & 396,97 \\
E & F & 107 & 5,33 & 570,31 \\
F & K & 107 & 9,82 & 1050,74 \\
G & H & 75 & 3,85 & 288,75 \\
H & I & 75 & 8,3 & 622,5 \\
\hline & Total & & $\mathbf{5 9 3 0 , 1 9}$ \\
\hline
\end{tabular}

Pengurangan jarak perpindahan bahan adalah sebesar $(14.495,08-5.930,19)=9.564,89 \mathrm{~m} / \mathrm{bulan}$. Sedangkan untuk perhitungan nilai jarak usulan dan jarak terpendek Euclidian dapat dilihat pada Tabel 5.

Table 5 Jarak Antar Stasiun pada Lantai Produksi Layout Usulan CORELAP

\begin{tabular}{cccc}
\hline $\begin{array}{c}\text { Stasiun } \\
\text { Awal }\end{array}$ & $\begin{array}{c}\text { Stasiun } \\
\text { Tujuan }\end{array}$ & $\begin{array}{c}\text { Jarak } \\
\text { Usulan }\end{array}$ & $\begin{array}{c}\text { Jarak } \\
\text { Eucludian }\end{array}$ \\
\hline A & B & 107 & 15,1 \\
B & C & 107 & 32,25 \\
C & D & 107 & 8,73 \\
D & E & 107 & 18,23 \\
E & F & 107 & 11,53 \\
F & G & 107 & 9,1 \\
G & H & 75 & 7,65 \\
H & I & 75 & 16,12 \\
I & J & 75 & 11,58 \\
J & K & 75 & 22,47 \\
\hline & Total & $\mathbf{6 2 , 8 9}$ & $\mathbf{5 9 , 1 9}$
\end{tabular}

$$
E=1-\frac{62,89-59,19}{59,19} \times 100 \%=93,74 \ldots .(4)
$$

\subsection{Penyusunan Layout dengan Menggunakan Algoritma ALDEP}

Penyusunan layout dengan algoritma ALDEP menggunakan software ALDEP. Input yang diperlukan dalammenggunakan Algoritma ALDEP antara lain adalah ukuran luas setiap stasiun kerja dan ARC (Activity Relationship Chart) stasiun kerja pada lantai produksi. Kemudian dalam menjalankan software ALDEP digunakan automatic search yang akan menghasilkan layout optimum dengan nilai TCR yang paling besar 


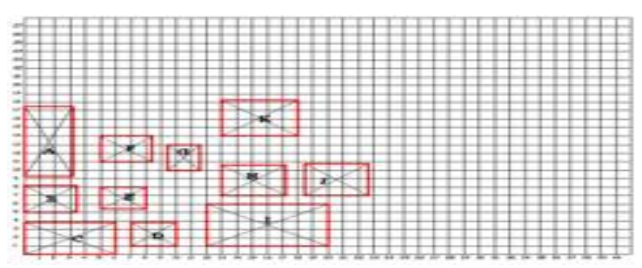

Figure 5 Block Layout Hasil Algoritma ALDEP

Table 6 Total Momen Perpindahan Material Antar Stasiun

\begin{tabular}{ccccc}
\hline Awal & Tujuan & Frekuensi Perpindahan & Jarak Stasiun & Momen \\
\hline A & B & 107 & 6,9 & 738,3 \\
B & C & 107 & 6 & 642 \\
C & D & 107 & 6 & 642 \\
D & E & 107 & 6,3 & 674,1 \\
E & F & 107 & 6 & 642 \\
F & K & 107 & 12,4 & 1326,8 \\
G & H & 75 & 7,3 & 547,5 \\
H & I & 75 & 6,2 & 465 \\
I & J & 75 & 9,96 & 747 \\
J & K & 75 & 12,6 & 945 \\
\hline
\end{tabular}

Pengurangan jarak perpindahan bahan adalah sebesar $(14.495,08-7.369,7)=7.12,38 \mathrm{~m} / \mathrm{bulan}$. Sedangkan untuk perhitungan nilai jarak usulan dan jarak terpendek Euclidiandapat dilihat pada Tabel 7. Perrhitungan efisiensinya adalah :

$$
\mathrm{E}=1-\frac{79,66-65,39}{65,39} \times 100 \%=78,18 \ldots .(5)
$$

Table 7 Jarak Antar Stasiun pada Lantai Produksi Layout Usulan ALDEP

\begin{tabular}{lccc}
\hline Awal & Tujuan & Jarak Stasiun & Momen \\
\hline A & B & 6,9 & 6,8 \\
B & C & 6 & 4,52 \\
C & D & 6 & 5,48 \\
D & E & 6,3 & 4,81 \\
E & F & 6 & 5,8 \\
F & K & 12,4 & 10,03 \\
G & H & 7,3 & 5,72 \\
H & I & 6,2 & 5,22 \\
I & J & 9,96 & 7,89 \\
J & K & 12,6 & 9,12 \\
\hline
\end{tabular}

\subsection{Simulasi Layout Menggunakan Software Flexsim}

Simulasi layout menggunakan Software Flexsim bertujuan untuk mengetahui jarak dan waktu optimal pada layout untuk mencapai target produksi yang didingkan perusahaan, Simulasi menggunakan software flexsim yang merupakan jenis program simulasi yang dapat memberikan gambaran mengenai jarak, waktu dn target produksi yang didinginkan. Gambar 6 dan 7 menunjukkan hasil simulasi dengan Software Flexsim. 


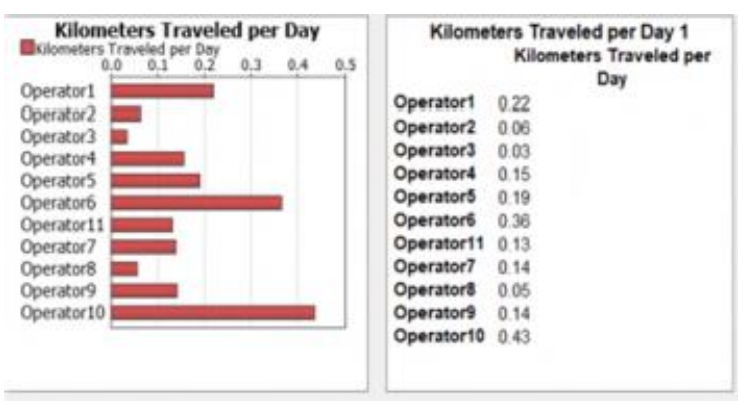

Figure 6 Hasil Simulasi Layout Usulan CORELAP Menggunakan Model Flexsim

Dari Gambar 6, Simulasi menggunakan software flexsim menghasilkan Kilometers

Traveled per Day 1,9 km/day

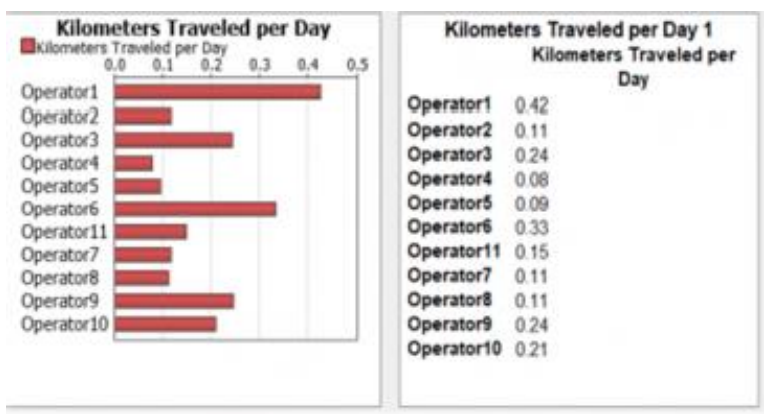

Figure 7 Hasil Simulasi Layout Usulan ALDEP Menggunakan Model Flexsim

Dari Gambar 6, Simulasi menggunakan software flexsim menghasilkan Kilometers Traveled per Day 2,09 km/day.

Dari dua alternative kajian di atas, maka dihasilkan kajian algoritma terbaik adalah dengan algoritma CORELAP, dimana pengurangan jarak perpindahan bahan sebesar 9.564,89 m/bulan dan efisiensi aliran bahan sebesar 93,74\% dengan Kilometers Traveled per Day 1,9 km/day.

\section{Kesimpulan}

Kesimpulan yang dapat diperoleh berdasarkan hasil perancangan yang telah dilakukan pada lantai produksi PT. ABC antara lain adalah sebagai berikut.

1. Total momen perpindahan pada lantai produksi PT. Indopura Utama pada kondisi aktual saat ini adalah sebesar 14.495,09 meter/bulan.

2. Total momen perpindahan pada lantai produksi PT. Indopura Utama dengan rancangan menggunakan algoritma CORELAP adalah sebesar 5930,19 meter/bulan, dan pada algoritma softwareALDEP adalah sebesar 7.369,7 meter/bulan.

3. Layout hasil algoritma CORELAP memberikan efisiensi jarak 93,74\% terhadap layout actual dan layout hasil software ALDEP memberikan efisiensi jarak $78,18 \%$.

4. Simulasi menggunakan software flexsim menghasilkan Kilometers Traveled 
per Day $1,9 \mathrm{~km} /$ day untuk algoritma CORELAP dan 2,09 km/day untuk software ALDEP.

5. Layout usulan yang terpilih merupakan layout hasil algoritma CORELAP dengan pengurangan jarak perpindahan bahan sebesar 9.564,89 m/bulan dan efisiensi aliran bahan sebesar 93,74\% dengan Kilometers Traveled per Day 1,9 $\mathrm{km} /$ day.

\section{REFERENSI}

[1] Wignjosoebroto, Sritomo. 2000. Tata Letak Pabrik dan Pemindahan Bahan. Edisi ke-3, Surabaya : Penerbit Guna Widya.

[2] Fred E. Meyers. Plant Layout and Material handling. Hal 158

[3] Prasad, Shankar. Material Handling Equipment Selection Using Weighted Utility Additive Theory. Journal of Industrial Engineering, 2013.

[4] Vieira, Pasa, Borsa. Materials Handling Management: A CASE STUDY. Journal of Operations and Supply Chain Management, 2011.

[5] Dannang, Dalliya. Improvement of Production Facility Layout of Fried Soybean using BLOCPLAN and CORELAP Method (A Case Study in UKM MMM Gading Kulon, Malang). Jurnal Teknologi dan Manajemen Agroindustri, 2017.

[6] Agustina, Maukar, Dewi. Perencanaan Produksi dan Perbaikan Tata Letak di PT. BERKAT ANUGRAH ALAM CEMERLANG. Widya Teknik, 2007.

[7] Asifa, Galih, Azis.Facility Layout Improvement: Based on Safety and Health at Work. 1990. Tata Letak Pabrik dan Pemindahan Bahan. Bandung: ITB Bandung, 1990.

[8] Rajesh, Naidu, Kumar.Plant Layout Optimization of Oven Manufacturing UNIT Using Corelap Algorithm. International Journal of Research in Engineering and Technology, 2016.

[9] Varsha, Sane, Darshan.Layout designing using Systematic Layout Planning for Division of a Manufacturing Facility. International Journal of Current Engineering and Technology, 2017.

[10] Ishak, Agustina, Livia.Perancangan Model Simulasi Untuk Meningkatkan Output Pada Divisi Assembly 14 di PT. PRATAMA ABADI INDUSTRI. Journal Industrial Manufacturing, 2017. 